\title{
EFFECT OF VISCOSITY MODIFYING AGENTS ON DEWATERING UNDER PRESSURE AND THE PERFORMANCES OF MORTAR AND CONCRETE
}

\author{
Upendra Neupane ${ }^{1}$, Parnthep Julnipitawong ${ }^{2}$, Somnuk Tangtermsirikul ${ }^{3}$, and Akino \\ Yusuke $^{4}$ \\ ${ }^{1}$ School of Civil Engineering and Technology, Sirindhorn International Institute of Technology, Thammasat \\ University, Bangkok, Thailand, e-mail: neupane.upendra@gmail.com \\ ${ }^{2}$ Construction and Maintenance Technology Research Center, School of Civil Engineering and Technology, \\ Sirindhorn International Institute of Technology, Thammasat University, Bangkok, Thailand, \\ e-mail: parnthep@siit.tu.ac.th \\ ${ }^{3}$ School of Civil Engineering and Technology, Sirindhorn International Institute of Technology, Thammasat \\ ${ }^{4}$ Performance Chemical Research, Kao Industrial (Thailand), Chonburi, Thailand, \\ e-mail: yakino@kao.th.com
}

Received Date: November 22, 2016

\begin{abstract}
This study emphasizes the effect of viscosity modifying agents (VMAs) on bleeding and dewatering of fresh mortars under high pressure. A detailed experimental dewatering device was designed and the analysis was carried out in order to evaluate the influence of two types of VMA on dewatering of freshly mixed mortars under high pressure. Additionally, the influence of the VMAs on mortar flow and air content of concrete was investigated. Two different types of VMA, which are a surfactant type and a starch ether type with various dosages were used in the tested mortar and concrete sample having the same water to binder ratio. Experimental results showed that by using dosages of surfactant type VMA equal to or higher than $3 \%$, the pressurized dewatering of the mortars was significantly reduced. The use of starch in mortar mixtures was ineffective to reduce dewatering of mortars under high pressure. At same water to binder ratio, the addition of surfactant type VMA slightly increased the mortar flow and the v-funnel flow time due to enhancement of the air content in mixtures whereas starch ether decreased the mortar flow and increased the v-funnel time. The results of this study indicate that the surfactant type VMA is useful to control the dewatering of concrete under high pressure.
\end{abstract}

Keywords: Bored piles, Dewatering, High pressure, Viscosity modifying agent

\section{Introduction}

Concrete is one of the most popular building materials and widely used for different types of construction worldwide. The quality of concrete is an important factor to make durable concrete structures [1]. One of the important factors that affects the quality of fresh concrete and durability of hardened concrete is the movement of water in fresh concrete which is generally called bleeding [2]. Bleeding is a form of segregation where some of the water in a freshly mixed concrete tends to drain out to the surface. It happens due to different specific gravity of various components of concrete. The heavier particles of concrete settle down faster while water, having the lowest specific gravity as compared to other components of concrete, moves up to the surface [3].

Various studies $[4,5,6,7,8]$ state that the amount of bleeding water depends on water to binder ratio, free water content, presence of fine particles, type and dosages of water reducing admixtures, shape and size of aggregate leading to their contact forces, permeability of concrete and pore pressure gradient in the fresh concrete. 
The concrete mixture is pressurized when it is placed under a deep bored pile. There is normal bleeding as well as internal bleeding or dewatering [9]. Due to the variation of pore pressure in a deep section, water is squeezed out from the concrete which is known as dewatering. The mechanism of dewatering in a bored pile is that water can flow under pore pressure gradient which is based on Darcy's law [10]. Variation of the pressure gradients and free water present in mixtures affect the bleeding and dewatering properties such as the rate and the amount of drained water [11]. Loh.et.al [12] studied the dewatering in terms of channeling in cement paste and mortar model pile. In both (paste and mortar models) cases dewatering started at a certain level from bottom and stopped before reaching the top surface. A large amount of drain water was trapped on the underside of reinforcement bar and aggregates which formed the abnormal cavities, weakening the bond strength between the constituents and reduced the strength and durability $[6,13]$.

Prediction of bleeding quantity from concrete is important in order to control the quality of the hardened mixtures. Conventional test methods [14, 15]are normally used to measure the normal bleeding. Till date, there are no any specific methods used to measure the dewatering of concrete under pressure in a bored pile. In many bored pile construction, the bleeding is considered to affect only the top part of the pile and this problem is normally solved by overcasting the piles and later trimming it to the cut off level[16]. This causes extra expenses to the construction of bored piles. But in the case of dewatering, there is no any appropriate method applied to control the dewatering of concrete in bored piles under pressure. Thus, abnormal cavities can be generated in the hardened concrete bored piles. Consequently, the presence of cavities leads to reduction of the strength and durability of bored piles. Therefore, the evaluation and control of the dewatering of fresh concrete under pressure is very significant to save the material, cost and to confirm the quality of the bored piles.

Currently, some Viscosity Modifying Agents (VMAs) are used to control the normal bleeding of concrete. Various studies [17, 18, 19, 20] describe that VMAs enhance the viscosity of its paste as well as increase the ability of cement paste to hold the constituent in suspension. It can be used to increase the resistance to bleeding and segregation of concrete [21, 22]. However, there is no experimental investigation on controlling the dewatering of concrete with VMA under high pressure.

Therefore, this study attempts to evaluate the effect of VMAs on dewatering of freshly mixed mortar under high pressure. A dewatering device was developed to experimentally measure the potential dewatering of fresh mortar under high pressure. Additionally, flow properties such as mortar flow, v-funnel speed were also tested in order to investigate the effect of VMAs on workability and viscosity of mixtures.

\section{Experimental Program}

The experiments were conducted to evaluate the effect of VMAs on dewatering of mortars under pressure. Additionally, their effect on flow properties (mortar flow and $\mathrm{v}$ funnel time) of mortar and air content in concrete were examined.

\section{Materials}

Ordinary Portland cement type I was used as a binder. Table 1 illustrates the chemical composition and physical properties of cement. The specific gravity and Blaine fineness of cement were 3.15 and $3100 \mathrm{~cm}^{2} / \mathrm{g}$, respectively. Natural river sand, conforming to ASTMC33-92 [23] with a specific gravity of 2.59was used as the fine aggregate. Crushed limestone was used as the coarse aggregate. Its maximum nominal size was $19 \mathrm{~mm}$ and 
specific gravity was 2.83. Two types of VMA, which area surfactant type, namely Viscotop 200LS (labeled as Surf 20K) and a starch ether type were used in the tested mortar and concrete mixtures.

Table 1. Chemical Compositions and Physical Properties of Portland Cement Type I

\begin{tabular}{|c|c|c|c|c|c|c|c|c|c|c|}
\hline \multirow[b]{2}{*}{ Binder } & \multicolumn{8}{|c|}{ Chemical compositions [\% by weight] } & \multirow{2}{*}{$\begin{array}{c}\text { Blaine's } \\
\text { fineness } \\
\left.\mathrm{cm}^{2} / \mathrm{g}\right]\end{array}$} & \multirow{2}{*}{$\begin{array}{l}\text { Specific } \\
\text { gravity }\end{array}$} \\
\hline & $\mathrm{SiO}_{2}$ & $\mathrm{Al}_{2} \mathrm{O}_{3}$ & $\mathrm{Fe}_{2} \mathrm{O}_{3}$ & $\mathrm{CaO}$ & $\mathrm{MgO}$ & $\mathrm{Na}_{2} \mathrm{O}_{3}$ & $\mathrm{SO}_{3}$ & $\mathrm{~K}_{2} \mathrm{O}$ & & \\
\hline OPC & 18.93 & 5.51 & 3.31 & 65.53 & 1.24 & 0.15 & 2.88 & 0.31 & 3100 & 3.15 \\
\hline
\end{tabular}

\section{Mix Proportions}

In this study, all the concrete and mortar mixtures were prepared by using water to binder ratio of 0.55 and sand to mortar ratio by volume of 0.46 . The control mixture of concrete (C0), having no VMA, was made with Ordinary Portland Cement (OPC) as the only binder. Two groups of freshly mixed concrete samples with different VMAs (Surf 20K and starch) were used to compare their effect on air content in concrete. First group consisted of four different mixtures with surfactant type VMA. This group consisted of concrete mixtures (C1- C4) containing Surf 20K with dosages of \%, 3\%, 5\% and 7\% by weight of water. Second group consisted of three mixes (C5-C7) having starch concentrations from $0.25 \%$ to $0.75 \%$ solution in unit water content in the mixture. The mortar mixtures (M0 M7) were prepared as representative samples of concrete (C0-C7), having the same water to binder ratio of 0.55 and sand to mortar ratio by volume of 0.46 . The mortar mixtures were tested to quantitatively measure the dewatering under high pressure and flow properties. Further details about the mix proportions of the tested concrete and mortar samples are shown in Table 2.

The mixing procedure for mortar and concrete with surfactant VMA was as follows;(1) dry constituents were mixed for $1 \mathrm{~min}$. (2) water was added and mixed for 1 min. (3) VMA (Surf 20K) was added and mixed for 2mins.

On the other hand, for starch ether VMA, the mixing procedure was; (1) dry constituents were mixed for 1 min. (2) starch was well mixed with water then added to the dry mixture and mixed for 3 mins.

The total mixing time of mortar and concrete with or without VMA (Surf 20K and starch) were $4 \mathrm{mins}$.

\section{Flow Properties of Mortars}

A mini slump cone according to European standard EN 1015-3 having a height of 60mm, atop and a bottom diameter of $70 \mathrm{~mm}$ and $100 \mathrm{~mm}$, respectively was used to determine the maximum spreading diameter of mortar flow. The flow time of the mixtures was measured by using the v-funnel test. The geometries and dimensions of the mini slump cone and the v-funnel are shown in Figure 1(a) and Figure 1(b), respectively.

\section{Air Content of Concrete}

An air meter according to ASTM C231 [24] was used to measure the air content in fresh concrete by using pressure method. The effect of VMA on air content of concrete was determined from the concrete mixtures containing various dosages of VMA. 
Table 2. Mix Proportions of the Prepared Concrete and Mortar Samples.

\begin{tabular}{|c|c|c|c|c|c|c|c|}
\hline $\begin{array}{c}\text { Mix } \\
\text { Designation }\end{array}$ & $\begin{array}{c}\text { Type of } \\
\text { VMA }\end{array}$ & $\mathbf{W} / \mathbf{b}$ & $\begin{array}{c}\text { Cement } \\
\mathbf{( k g / \mathbf { m } ^ { 3 } )}\end{array}$ & $\begin{array}{c}\text { Sand } \\
\mathbf{( k g / \mathbf { m } ^ { 3 } )}\end{array}$ & $\begin{array}{c}\text { Gravel } \\
\mathbf{( k g / \mathbf { m } ^ { 3 } )}\end{array}$ & $\begin{array}{c}\text { Water } \\
\left(\mathbf{k g} / \mathbf{m}^{\mathbf{3}} \mathbf{)}\right.\end{array}$ & $\begin{array}{c}\text { VMA /w } \\
\mathbf{( \% )}\end{array}$ \\
\hline C0 & - & 0.55 & 373 & 743 & 1076 & 205 & 0 \\
\hline C1 & Surf 20K & 0.55 & 373 & 743 & 1076 & 205 & 1 \\
\hline C2 & Surf 20K & 0.55 & 373 & 743 & 1076 & 205 & 3 \\
\hline C3 & Surf 20K & 0.55 & 373 & 743 & 1076 & 205 & 5 \\
\hline C4 & Surf 20K & 0.55 & 373 & 743 & 1076 & 205 & 7 \\
\hline C5 & Starch & 0.55 & 373 & 743 & 1076 & 205 & 0.25 \\
\hline C6 & Starch & 0.55 & 373 & 743 & 1076 & 205 & 0.5 \\
\hline C7 & Starch & 0.55 & 373 & 743 & 1076 & 205 & 0.75 \\
\hline M0 & - & 0.55 & 613 & 1187 & - & 337 & 0 \\
\hline M1 & Surf 20K & 0.55 & 613 & 1187 & - & 337 & 1 \\
\hline M2 & Surf 20K & 0.55 & 613 & 1187 & - & 337 & 3 \\
\hline M3 & Surf 20K & 0.55 & 613 & 1187 & - & 337 & 5 \\
\hline M4 & Surf 20K & 0.55 & 613 & 1187 & - & 337 & 7 \\
\hline M5 & Starch & 0.55 & 613 & 1187 & - & 337 & 0.25 \\
\hline M6 & Starch & 0.55 & 613 & 1187 & - & 337 & 0.5 \\
\hline M7 & Starch & 0.55 & 613 & 1187 & - & 337 & 0.75 \\
\hline
\end{tabular}

C: Concrete, M: Mortar, VMA: viscosity modifying agent, W: water

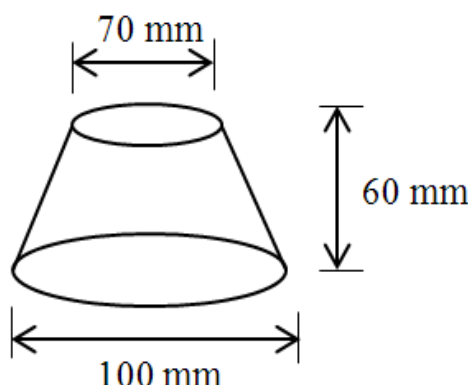

(a) Minislump cone
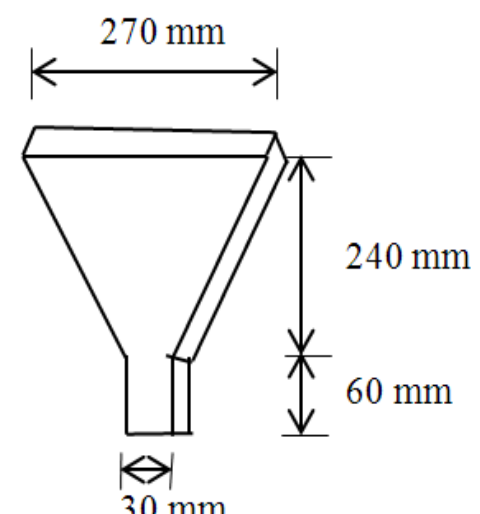

$30 \mathrm{~mm}$

Figure 1. Apparatus for measuring the flow properties of mortars. 


\section{Instrument for Dewatering Test and Test Methods}

To measure the dewatering of the mortar mixtures under high pressure, a cylindrical pressure vessel was developed. The schematic and experimental setup of the developed dewatering device are shown Figure 2(a) and Figure 2(b), respectively. The device with an internal diameter of $80 \mathrm{~mm}$ and a height of $330 \mathrm{mmwas}$ fabricated using stainless steel. The cross sectional area of the test sample was thus $5024 \mathrm{~mm}^{2}$.A porous stone (100mm diameter and $6 \mathrm{~mm}$ thickness) was fixed at the bottom of the device to filter the drained water from the mortar sample. A filter paper was placed at the top of the porous stone before filling the cylinder with mortar samples for protecting the porous stone from clogging. Drained water from the samples was collected and measured periodically with a weight balance.

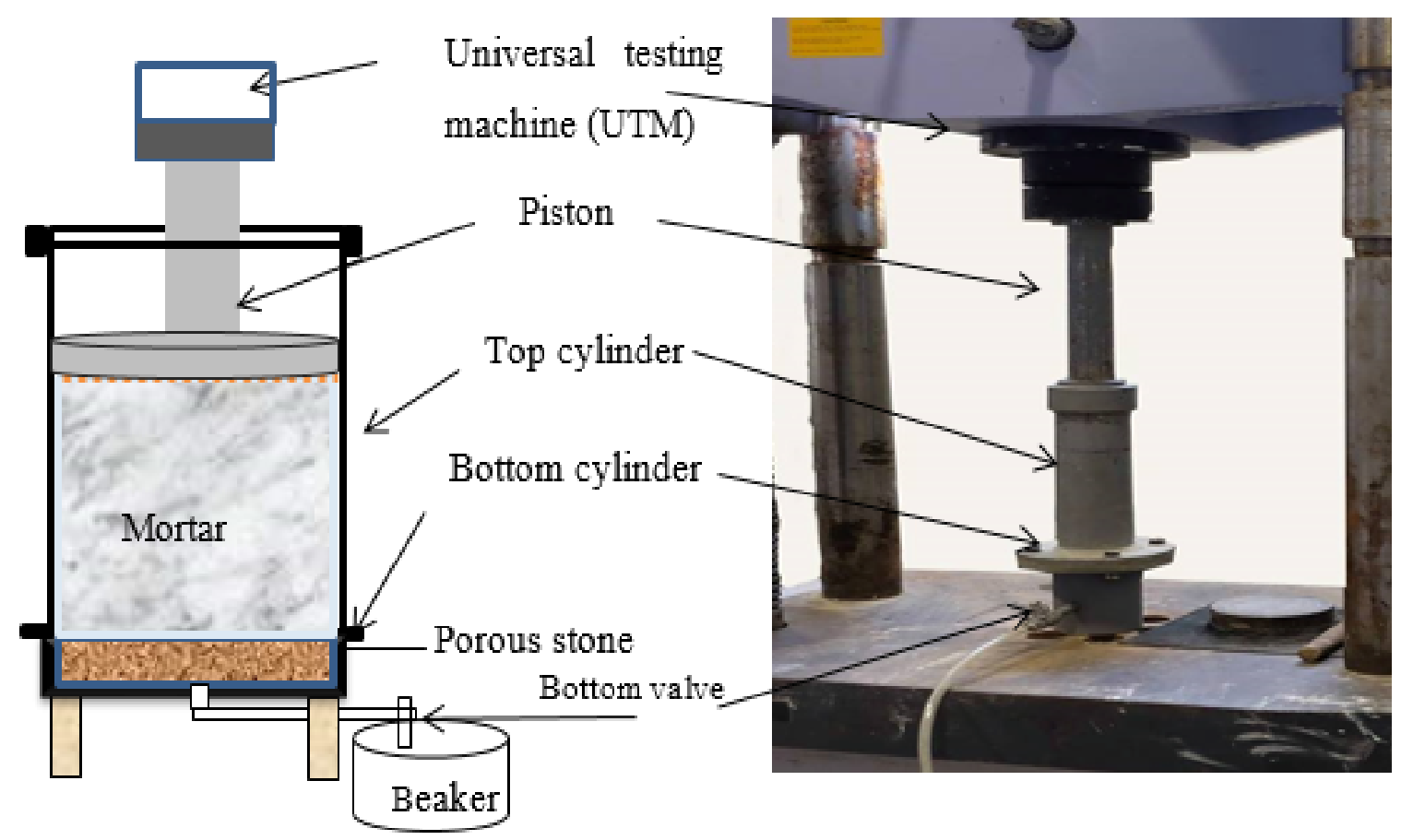

(a) Schematic test setup

(b) Laboratory test setup

Figure 2. Dewatering device for dewatering test

Five steps of dewatering measurements were conducted to evaluate the dewatering for each sample, i.e., (1) a freshly mixed mortar sample was placed in the dewatering device up to height of $250 \mathrm{~mm}$ while the bottom valve was closed. (2) A force of $3.62 \mathrm{kN}$ with a stroke of $6 \mathrm{~mm} / \mathrm{min}$ was applied directly to the sample through a piston in order to create pressure on the sample corresponding to a self-weight pressure of a bored pile at $30 \mathrm{~m}$ deep. (3) Apply the force and sustain it on the sample till reaching $0.72 \mathrm{MPa}$ while the bottom valve is closed. (4) Open the bottom valve after reaching the target pressure. Continue applying the force on the sample till the sample is finally consolidated. (5) The drained water from the sample during the pressurization is collected and measured periodically after opening the bottom valve.

The accumulated dewatering percentage, $\mathrm{d}(\mathrm{t})$, is calculated according to ASTM C232. Dewatering percentage $\mathrm{d}(\mathrm{t})$ expressed as the percentage of the unit water content in the mixture (Kim et al., 2014; Yim et al., 2014), as follows 


$$
\mathrm{d}(\mathrm{t})=\frac{w(t)}{W A H} \times 100
$$

where $\mathrm{w}(\mathrm{t})$ is the total amount of drained water $(\mathrm{kg})$ at time $\mathrm{t}(\mathrm{min}), \mathrm{W}$ is unit water content of the mixtures $\left(\mathrm{kg} / \mathrm{m}^{3}\right)$, A is the cross-sectional area of the sample $\left(\mathrm{m}^{2}\right)$ and $\mathrm{H}$ is the initial height of the sample (m).

\section{Results and Discussion}

\section{Effect of VMAs on Mortar Flow}

The effects of surfactant type VMA on mortar flow and v-funnel flow time are shown in Figure 3(a) and Figure 3 (b), respectively. It can be seen that the surfactant type VMA (Surf 20K) slightly increases the mortar flow and prolongs the v-funnel flow time. The mortar flow of control mortar with $0 \%$ Surf $20 \mathrm{~K}$ was $138 \mathrm{~mm}$ whereas mortar containing $1 \%$ surfactant type VMA reduces the mortar flow from $138 \mathrm{~mm}$ to $136 \mathrm{~mm}$, while after that it slightly increases the mortar flow as compared to the control mortar. By considering the same mortar mixtures, v-funnel flow time increases with increasing the dosages of Surf $20 \mathrm{~K}$. Between $0 \%$ to $5 \%$, the v-funnel flow time increases moderately, while after that it rises significantly at $7 \%$. This is because the surfactant molecules have a hydrophilic head and a hydrophobic end as shown in Figure 4. Hydrophilic head has strong attraction with the liquid phase i.e. mixing water of mortar or concrete. The hydrophobic tails of surfactant molecules stick out of the solution and reduce distortion of water molecules. The mutual repulsion between the hydrophilic heads of surfactant reduces the attraction of the bulk liquid phase and reduces the surface tension of the liquid phase and makes it easier to produce air bubbles in the mixtures [25]. These air bubbles contribute to increase the mortar flow [26]. At the same time, surfactant forms micelle net structures in the liquid phase, which increase the viscosity of the mixtures. Therefore, mortars with surfactant have longer v-funnel time.
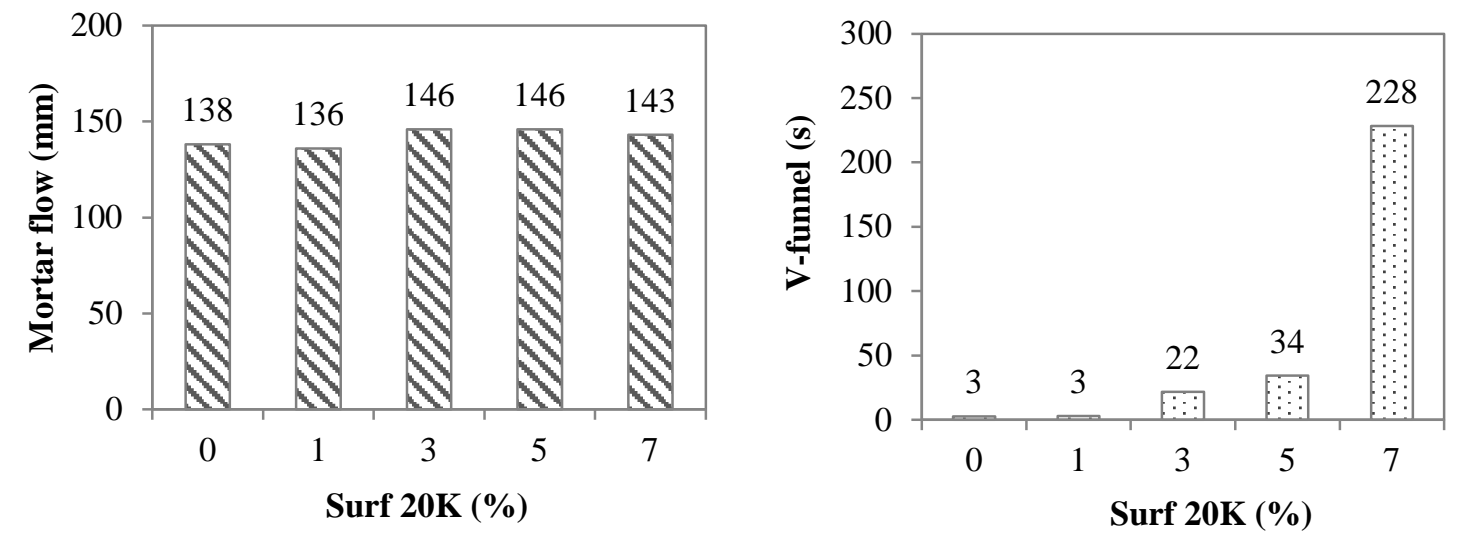

(a)Mortar flow(b) V-funnel time

Figure 3. Effect of surfactant on flow properties

The influences of the addition of starch on flow properties, mortar flow and $\mathrm{v}$ funnel time, are presented in Figure 5(a) and Figure 5(b), respectively. Increasing the dosage of starch from $0 \%$ to $0.75 \%$ significantly reduces the mortar flow. The mortar without starch shows a mortar flow of $138 \mathrm{~mm}$ whereas mortar containing $0.25 \%$ starch 
concentration has a flow of $118 \mathrm{~mm}$.By increasing the dosages to $0.5 \%$ and $0.75 \%$, the mortars show flow vales slightly above $100 \mathrm{~mm}$, indicating very low deformability. On the other hand, the v-funnel flow times increase with increasing dosages of starch. The vfunnel flow time of mortars was not measurable at the dosages equal or exceeding $0.5 \%$ because the mixtures had too high viscosity. It is because starch makes the mortar more viscous by increasing the viscosity of the liquid phase.

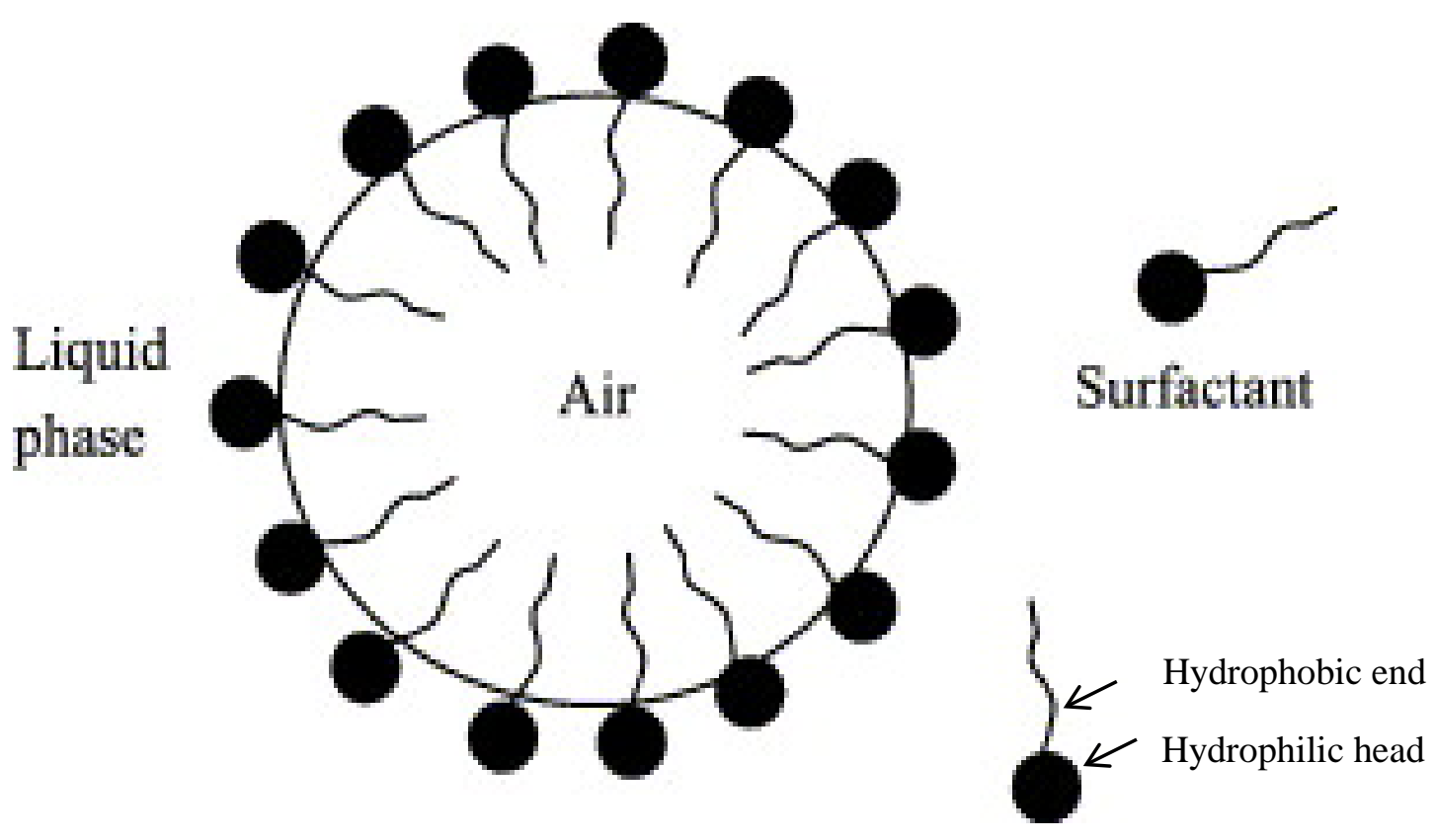

Figure 4. Distribution of surfactant molecules at the water-air interface [25]

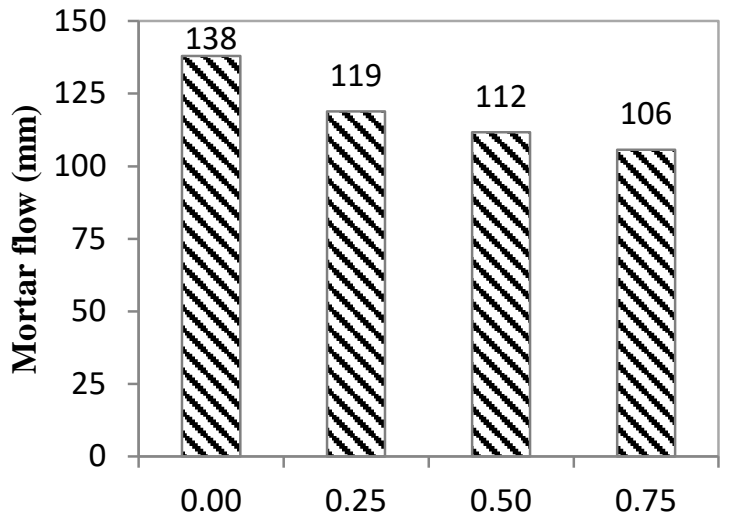

Starch (\%)

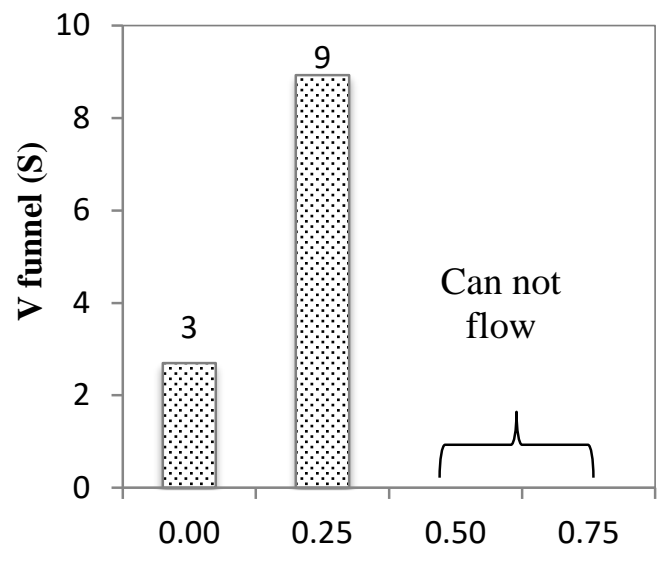

Starch (\%)

(a)Mortar flow(b) V-funnel time

Figure 5. Effect of starch on flow properties 


\section{Effect of VMAs on Air Content of Concrete}

The effect of surfactant type VMA (Surf20K) on air content of concrete is presented in Figure 6. It can be seen that increasing the dosages of surfactant increase the air content of the concrete mixtures. It is because surfactant produces the air bubbles in concrete mixtures by reducing the surface tension of mixing water. Moreover, the surfactant can be adsorbed on cement surface which can also contribute to formation of some air bubbles in the mixtures [25]

Figure 7 illustrates the effect of starch on air content of concrete. It can be observed that the use of starch slightly increases the air content in concrete. The air content of concrete without starch (C0) is $1.4 \%$. By increasing the concentration of starch to $0.75 \%$ in the same mixture condition, the air increases to $2.0 \%$. The increase of air is less significant when compared to the case of surfactant VMA. Therefore, flow of mortars with starch does not increase but on the other hand reduces due to increase in viscosity.

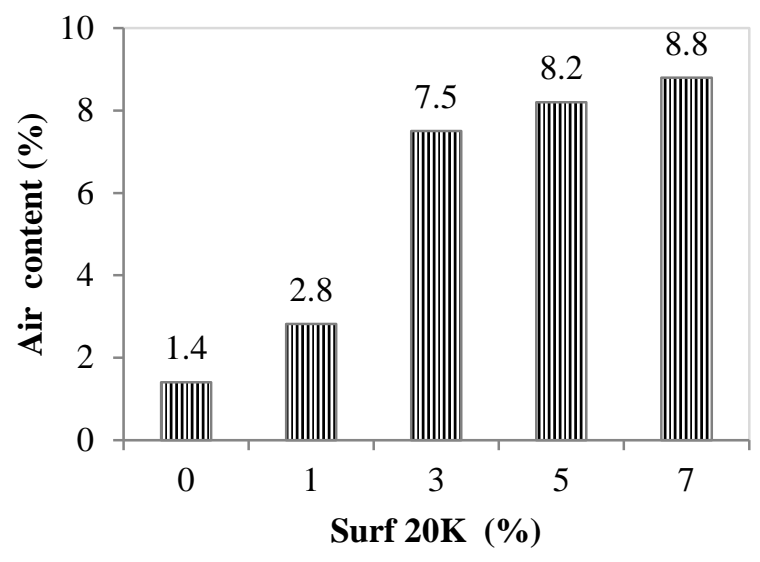

Figure 6. Effect of Surf $20 \mathrm{~K}$ on air content of concreteof concrete

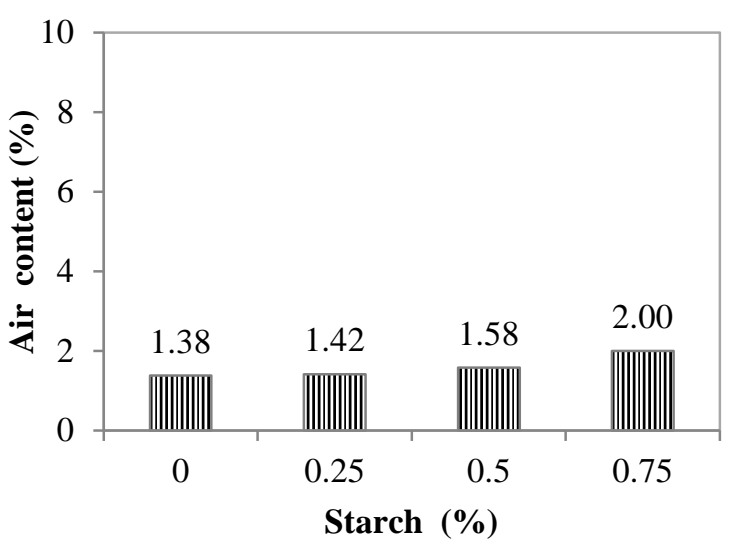

Figure 7. Effect of starch on air content of concrete

\section{Effect of VMAs on Dewatering of Mortar under High Pressure}

The influence of surfactant type VMA (Surf 20K) on dewatering of mortar under highpressure $(0.72 \mathrm{MPa})$ is shown in Figure 8. It can be observed that the accumulated dewatering of control mortar (M0) without Surf20K is35.3\% and by adding1.0\% dosage of Surf 20K, there is no significant effect on dewatering. However, with an increase of the Surf $20 \mathrm{~K}$ dosages from $3.0 \%$ to $7.0 \%$, the dewatering reduces effectively to $13.0 \%$ and $4.07 \%$, respectively. This is because the surfactant forms a higher order molecular structure by micelle aggregation of two different parts of surfactant molecule, which are a hydrophilic and a hydrophobic end as shown in Figure 9. Moreover, the surfactant produces threadlike micelle net structures in the fresh cement paste mixture as can be confirmed by a SEM image in Figure 10. It can be observed that the network of threadlike micelles in the liquid phase covers the cement particles throughout the mixtures. This micelle net structure lowers the amount of free water in the cement paste mixtures by holding the water within its structure, reducing the permeability of the fresh mixtures and increasing the stiffness of the fresh paste mixtures. When pressured, mixtures having low amount of free water, lower permeability and higher solid phase stiffness expel lower 
amount of water. Therefore, the pressurized dewatering amount of the mortar reduces by using the Surf $20 \mathrm{~K}$.

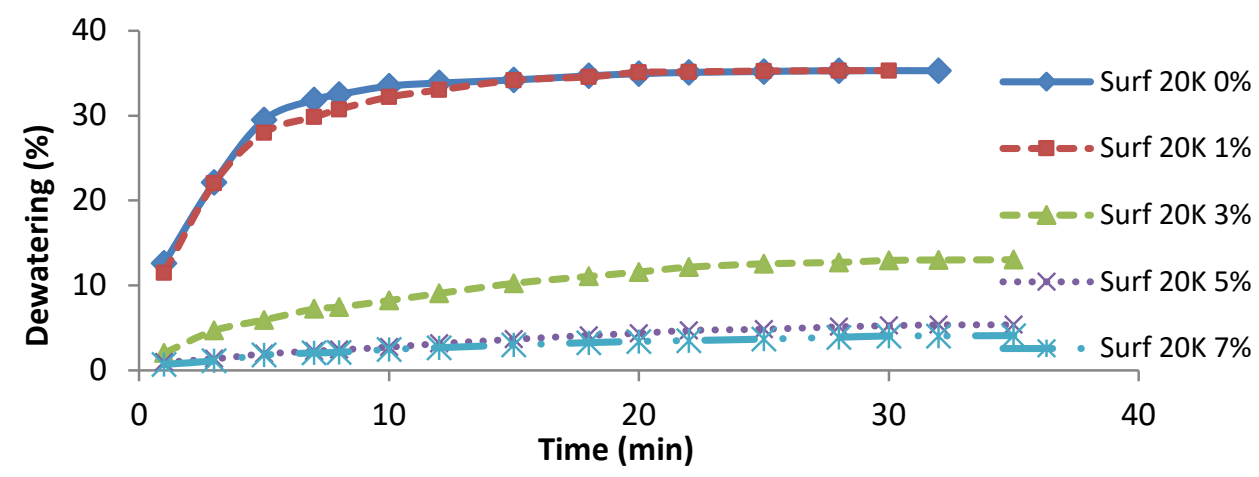

Figure 8. Effect of Surf 20K on dewatering under pressure

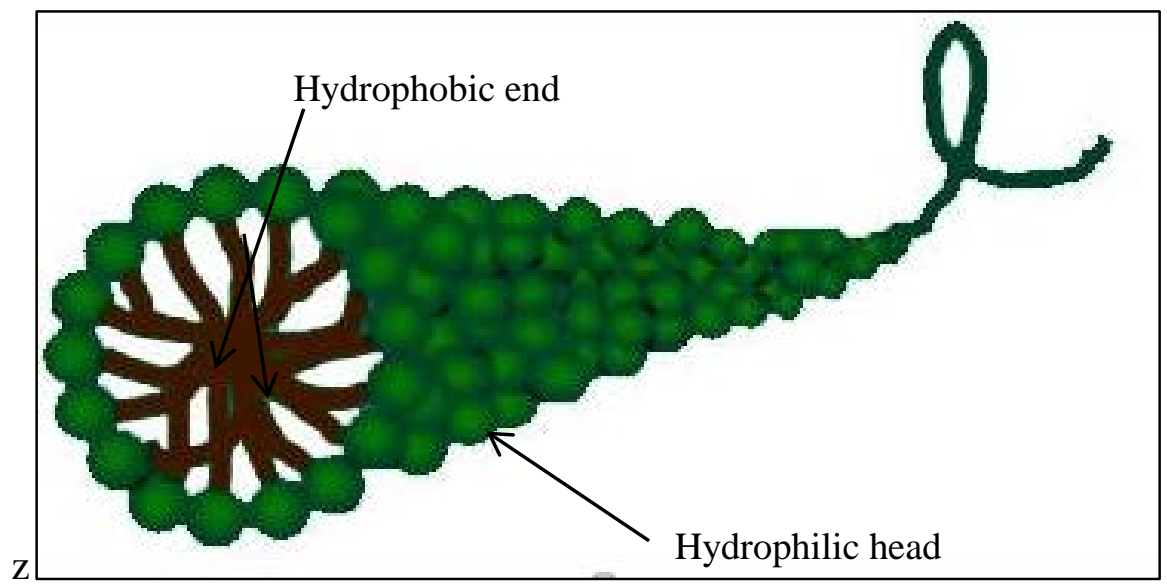

Figure 9. Thread like micelle net structure of surfactant molecule

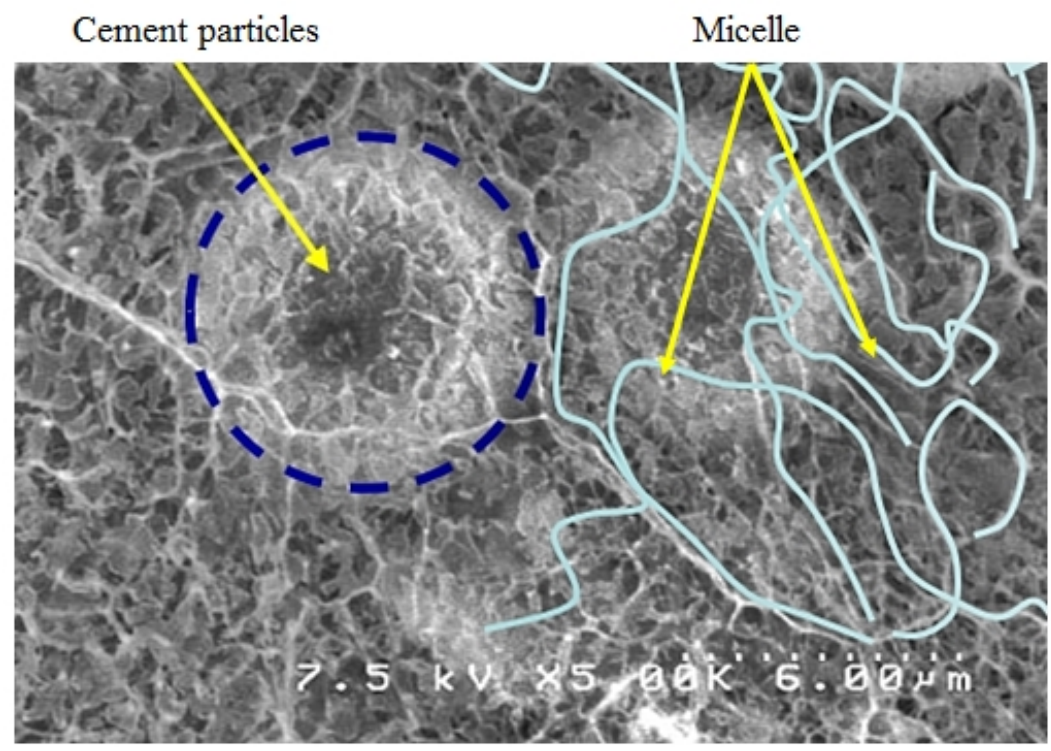

Figure 10. Network of threadlike micelle in water phase covers cement particles (fresh cement slurry having $\mathrm{w} / \mathrm{c}=1$ at magnification of image $5000 \mathrm{x}$ ) 
The second group of samples, M5 to M7 mortarshavingconcentration of starch ranging from $0 \%$ to $0.75 \%$,were tested to measure the dewatering of the mortars under pressure. Figure 11 shows the dewatering results with various concentraions of starch from $0 \%$ to $0.75 \%$. It is shownthat even adding highdosagesof starch up to $0.75 \%$ concretration,itslightly reduces the dewatering under pressure.Ascomparing thedewatering of the control mortar(M0) with the mortar having $0.75 \%$ starchconcentraion,dewatering only reduces from $35.3 \%$ to $29.4 \%$.It is becausestarch only increases viscosity of the mixed water without the ablilities to restain water, to reduce permeablility and to increase stiffness of the mixtures when compared to those of surfactant type (Surf 20K) VMA.

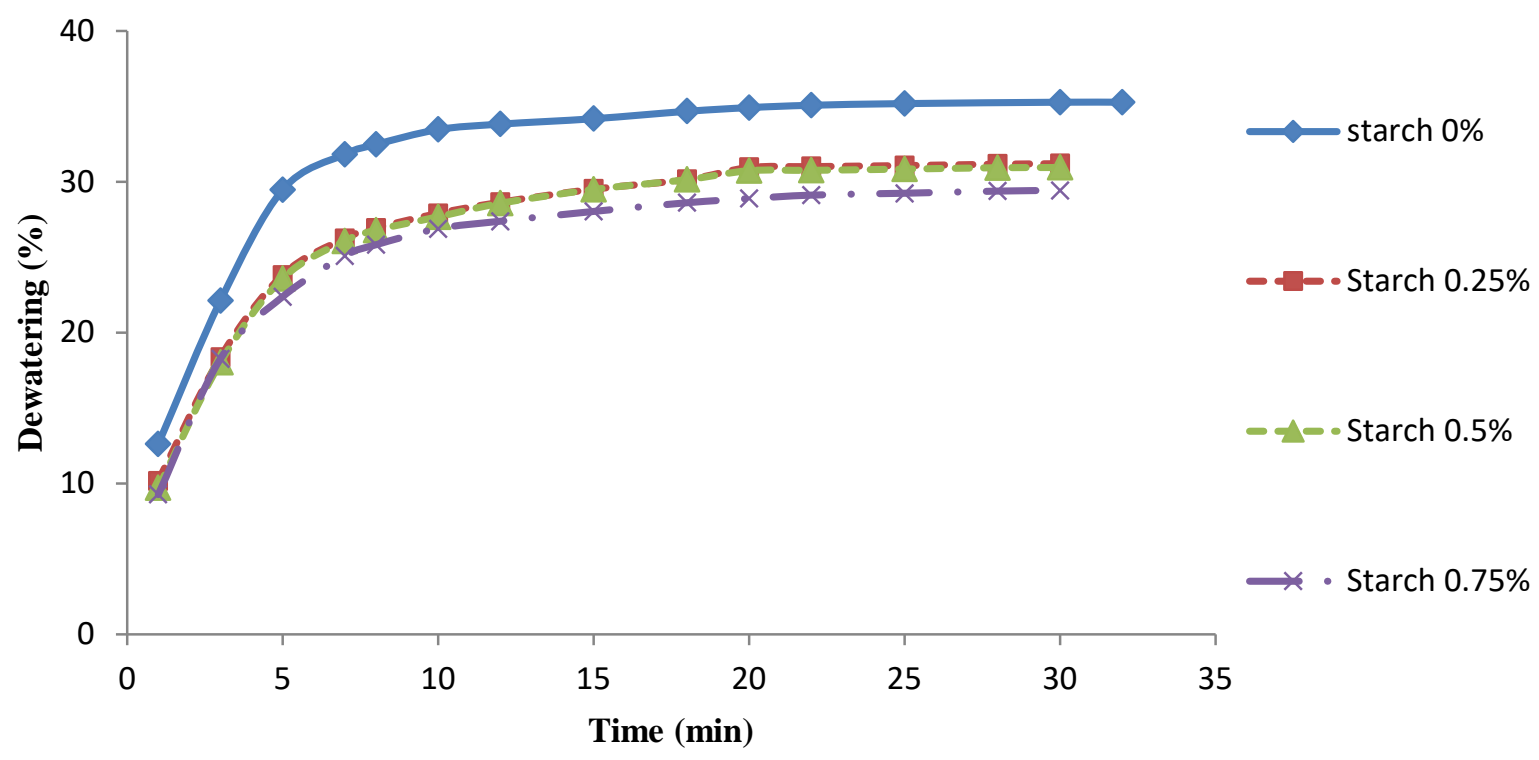

Figure 11. Effect of starch on dewatering under pressure

\section{Conclusions}

The effect of VMAs on dewatering under pressure and flow properties of various fresh mortars is demonstrated in this work and the following conclusions can be drawn based on the results obtained from this experimental study.

- Dewatering resistance of fresh mortar increases with an increase of the dosage of surfactant type VMA. The dosages of Surf $20 \mathrm{~K}$ at $3 \%$ or higher effectively reduce the dewatering amount under pressure. On the other hand, starch ether is not able to improve the dewatering resistance under pressure.

- Surf $20 \mathrm{~K}$ slightly increases the mortar flow because surfactant molecule has hydrophobic and hydrophilic parts which help to form small air bubbles in mortars. However, it increases the flow time (v-funnel test) due to increase of viscosity. On the other hand, starch decreases the mortar flow and increases the flow time.

\section{Acknowledgement}

The authors would like to thank the Kao Corporation for providing research support and sample for this study. The authors also acknowledge the Centre of Excellence in Material Science, Construction and Maintenance Technology, Thammasat University, Thailand and National Research University Project for supporting this research study. 


\section{References}

[1] M. Vaishnavi, and M.K. Rao, "Durability of High Volume Flyash Concrete,” In: Advanced in Structural Engineering Materials Volume 3, V. Matsagar, ed.: Indian Institute of Technology (IIT) Delhi, pp. 1823-1836, 2015.

[2] T.C. Powers, The Properties of Fresh Concrete, John Wiley \& Sons, NewYork, United States of America, 1968.

[3] A.M. Nevil, Properties of Concrete, $5^{\text {th }}$ Edition, Monotype Times, Malaysia, 2011.

[4] K. Thumasujarit, and S. Tangtermsirikul, "Experimental investigation on bleeding of fly ash concrete," Research and Development Journal of the Engineering Institute of Thailand,Vol. 15, No. 3, pp. 40-47, 2004.

[5] K. Thumasujarit, and S. Tangtermsirikul, "Experimental study on bleeding of Fly ash concrete with water reducing admixtures," Research and Development Journal of the Engineering Institute of Thailand, Vol. 16, No. 3, pp. 1-7, 2005.

[6] M. Hoshino, "Relationship between bleeding of coarse aggregate and specimen height of concrete,” ACI Material Journal Vol. 2, pp. 185-190, 1989.

[7] S. Tangtermsirikul, A. Nanayakara, and K. Maekawa "Mathematical model for dewatering of fresh concrete under compression," In: Proceedings of The Second East Asia-Pacific Conference on Structural Engineering and Construction, Vol. 1, pp. 469-474, 1989.

[8] H.J. Yim, J.H. Kim, H.G. Kwak, and J.K. Kim, "Evaluation of internal bleeding in concrete using a self-weight bleeding test," Cement and Concrete Research, Vol. 53, pp. 18-24, 2013.

[9] Y.C. Kog, "Bleeding and channeling in bored piles,” Magazine of Concrete Research, Vol. 10, pp. 759-765, 2009.

[10] S. Tangtermsirikul, and K. Maekawa, "Simulation of dewatering of fresh concrete under mechanical pressure," In: Proceedings of the $43^{\text {th }}$ Annual Conference of JSCE, pp. 364-365, 1988.

[11] H.J. Yim, J.H. Kim, and H.G. Kawak "Experimental simulation of bleeding under high concrete column,” Cement and Concrete Research, Vol. 57, pp. 61-69, 2014.

[12] C.K. Loh, S.K. Tan, K.Y. Tan, and T.W. Wee, "An experimental study of bleeding and channeling of cement paste and mortar," Advanced in Cement Research, Vol. 10, pp. 116, 1998.

[13] K.H. Khayat, "Use of viscosity modify admixture to reduce the top bar effect of anchored bars cast with fluid concrete,” ACI Material Journal, pp.158-167, 1998.

[14] ASTM International, "Standard test methods for bleeding of concrete,” ASTM C 232-99, Annual Book ASTM Standards, 1999.

[15] ASTM International, "Standard test methods for bleeding of Concrete," ASTM C243-95, Annual Book ASTM Standards, 1995. 
[16] Z.J. Sliwinski, and W.G.K. Fleming, “The integrity and performance of bored piles,” In: Proceedings of the International Conference on Advances in Piling and Ground Treatment, Thomas Telford, London, pp. 211-223, 1983.

[17] M. Lachemi, K.M.A. Hossain, V. Lambros, P.-C. Nkinamubanzi, and B.N. Bouzoubaâ "Performance of new viscosity modifying admixtures in enhancing the rheological properties of cement paste,” Cement and Concrete Research, Vol. 34, pp.185-193, 2004.

[18] K.H. Khayat, "Viscoisty enhancing admixtures for cemnet based materials-An overview," Cement and Concrete Composites, Vol. 20, pp.171-188, 1998.

[19] M. Lachemi, K.M.A. Hossaina, V. Lambrosa, P.-C. Nkinamubanzi, and B.N. Bouzoubaâb "Self-consolidating concrete incorporating new viscosity modifying admixtures," Cement and Concrete Research, Vol. 34, pp. 917-926, 2004.

[20] S. Rols, J. Ambroise, J. Péra, "Effects of different viscosity agents on the properties of concrete," Cement and Concrete Research, Vol. 29, pp. 261-266,1999.

[21] The European Federation of Specialist Construction Chemicals and Concrete Systems, "Guidelines for Viscosity Modifying Admixture for Concrete," The European Fedration of Concrete Admixture Association, 2006.

[22] K.H. Khayat, and Z. Guizani, "Use of viscosity modifying admixture to enhance stability of fluid concrete,” ACI Materials Journal, Vol. 94, pp. 332-340, 1997.

[23] ASTM International, "Standard specification for concrete aggregates," ASTM C33-92 Annual Book ASTM Standards, 1992.

[24] ASTM International, "Standard test method for air content of freshly mixed concrete by the pressure method,” ASTM C231-03, Annual Book ASTM Standards, 2003.

[25] L. Du, and K.J. Folliard, "Mechanism of air entrainment in concrete," Cement and Concrete Research, Vol. 35, pp. 1463-1471, 2005

[26] M. Malivagana, Miscellaneous Admixtues,Concrete Admixtures Handbook, $2^{\text {nd }}$ Edtion, V. S. Rama-Chandra Nyoes Publication, Park Ridge, New Jersey, United States of America, 1995. 